\title{
Depression and Thanatosis - an evolutionary perspective
}

Co-authors: Bohdan Wasilewski 1, Eugene Egan 2.

1 Psychosomatic Institute and, IPS Medical Center, Warsaw, Poland.

2 Dingle Medical Centre, Medical Centre, Dingle, Ireland.

\section{Objectives:}

The authors postulate that the old phylogenetic mechanism prompting depression is protective in nature and as with pain, triggers a cascade of defensive reactions. When persistent however, such reactions reinforced by negative social factors are activated in a way comparable to apoptosis. The result is destruction of the "self " in a process we term Thanatosis (Wasilewski B., 2004)

\section{Background:}

The presentation contains preliminary conclusions of work by an interdisciplinary team analyzing depression from anthropological and cultural perspectives

\section{Materials and Methods:}

The source and pathogenesis of depression remains unclear. Intensive research has failed to halt its ever increasing incidence and prevent it becoming a major civilizational threat. Depression was analyzed from an evolutionary adaptationist standpoint (Price J. at all, 1994). The working team included: psychiatrists, general practitioners, anthropologists, philosophers, psychologists, psychotherapists, met three times at the working sessions in 2014-2018

\section{Results and Conclusions:}

The authors consider depression as the expression of a phylogenetic (evolutionary) protective mechanism in the short term, but which if persistent, catalyses biological and psychological processes to effect self-elimination. This is achieved by inhibiting biological defence mechanisms and activating civilizational diseases such as cancer, a process which in humans we designate as Thanatosis. It differs from an analogous reaction in animals (Jones R.B., 1986) who lack the social component

\section{Literature:}

Wasilewski B, 2008. Depression accompanying somatic illnessesparallel illness or adaptive mechanism? "W: XXVII European Conference on Psychosomatics Research (ECPR) Advances in Liaison Psychiatry and Psychosomatics in Europe, Zaragoza, Spain June 25-28th, 2008, Auditorium-Palacio de Congresos - Abstracts, 70-71

Wasilewski B, 2014. Psychosomatic functioning of individuals in evolutionary perspective. J Psychosomatic Res 76: 519

Wasilewski B, Egan E, 2018. The Psychosomatic functioning of individuals from an evolutionary perspective, new understandings of depression. Abstracts: Social Pathologies of Contemporary Civilization Conference, Nov. 2-3, 2018; UCC, Cork, Ireland, 13

\section{Conclusions:}

The classic, nosological model of understanding disease is inadequate to explain depression and we believe an evolutionary, adaptationist analysis is necessary. The mechanism of Thanatosis may therefore be an important element in the pathogenesis of civilizational diseases (Wasilewski B., Egan E., 2018)

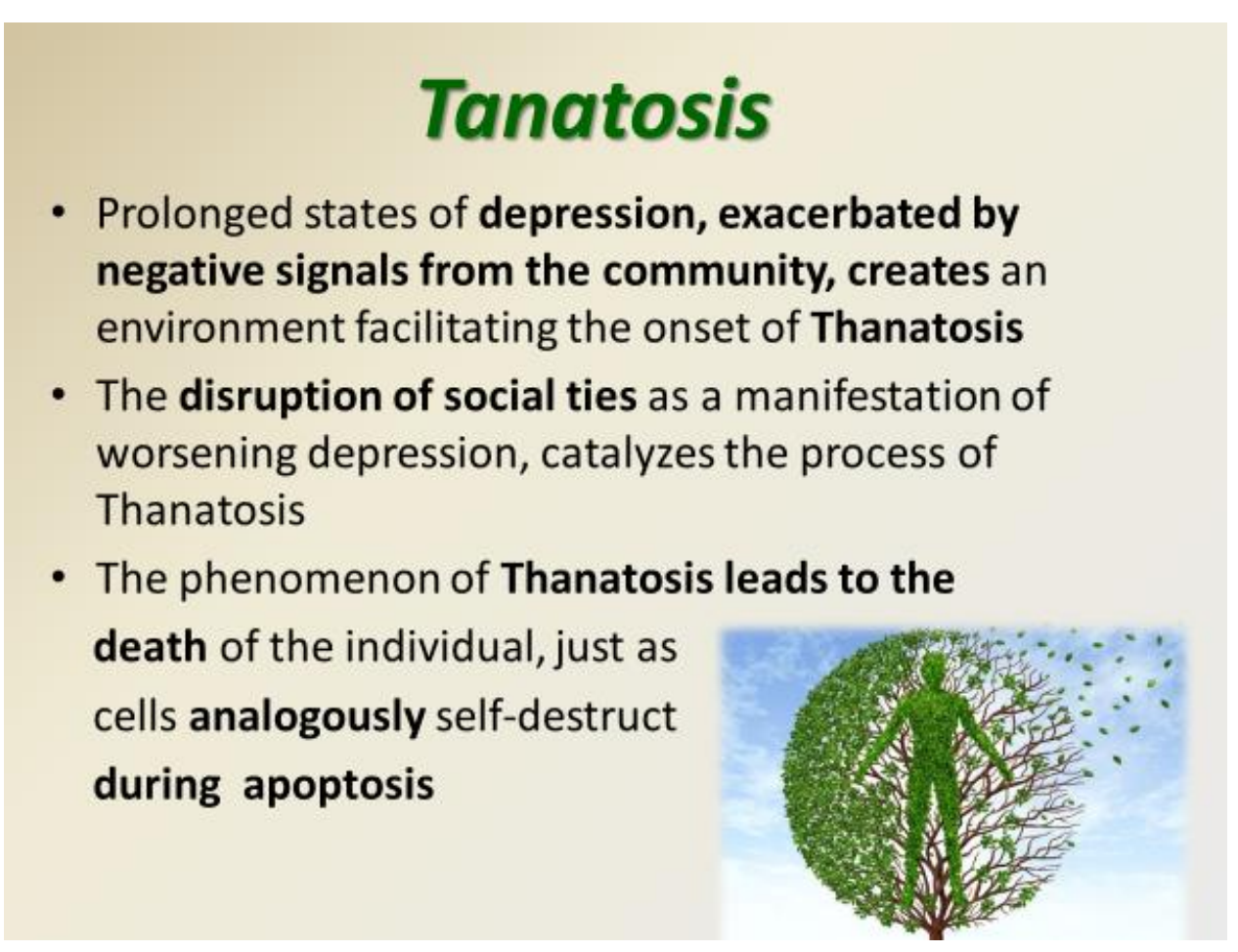

\section{Programmable Death}
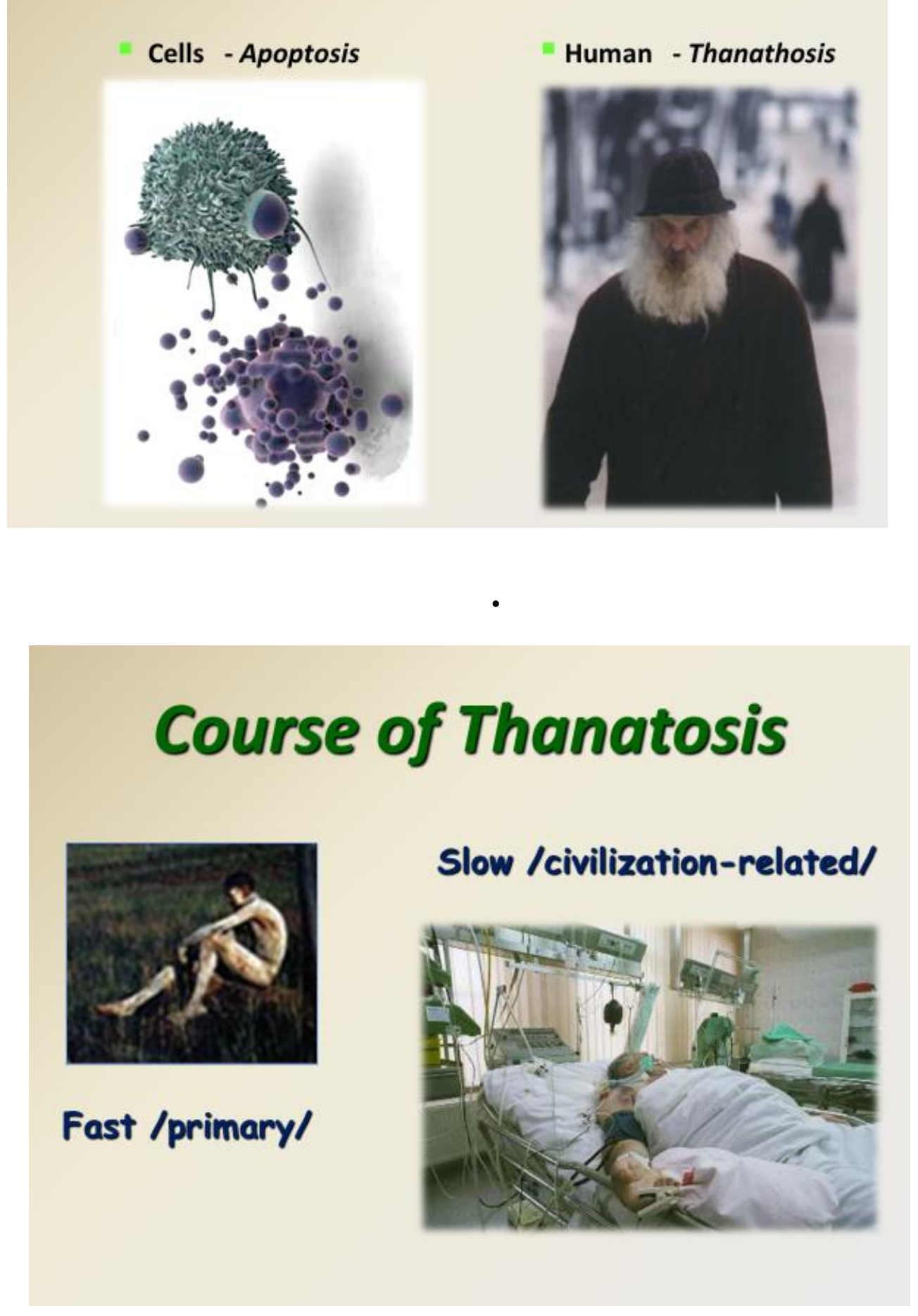